\title{
Effects of Kimchi Powder or Lactobacillus plantarum Added Fermented Sausages on Serum Lipid and Cholesterol Levels in Rats
}

\author{
Jin-Wook Lee, Chang-Won Pyun, Go-Eun Hong, Kyu-Ho Han ${ }^{1}$, Kang-Duk Choi ${ }^{2}$, and Chi-Ho Lee* \\ Department of Food Science and Biotechnology of Animal Resources, \\ College of Animal Bioscience and Technology, Konkuk University, Seoul 143-701, Korea \\ ${ }^{1}$ Department of Agriculture and Life Science, Obihiro University of Agriculture and Veterinary Medicine, \\ Obihiro, Hokkaido 080-8555, Japan \\ ${ }^{2}$ Graduate school of Bio and Information Technology, Hankyong National University, Ansung 456-749, Korea
}

\begin{abstract}
This study was performed to investigate the serum lipid and cholesterol lowering effects of kimchi powder or Lactobacillus plantarum when added to fermented sausage in rats. Male SD (Sprague-Dawley) rats were divided in three groups and administered with the following diets for $6 \mathrm{wk}$ : non-fermented sausage added diets (CON), kimchi fermented sausage added diets (KIM), and Lactobacillus plantarum fermented sausage added diets (PLA). The CON has significantly $(p<0.05)$ higher food intake, body weight gains, and final body weight than the other two groups. The body weight of KIM was significantly $(p<0.05)$ lower than that of the other groups. The weights of organs (heart, lung, liver, kidney, spleen, perirenal adipose tissue, and epididymal adipose tissue) were not affected by any treatments. The mean value of serum triglycerides (TG) concentration in KIM and PLA groups was not significantly different compared with CON. Total cholesterol, low density lipoprotein and high density lipoprotein levels in serum of KIM were significantly $(p<0.05)$ lower than those of CON. The serum free cholesterol level and atherogenic index (AI) in KIM and PLA were significantly $(p<0.05)$ lower than those of CON. In conclusion, dietary supplementations with kimchi powder fermented sausages or L. plantarum fermented sausages were effective for lowering serum lipid, cholesterol levels and atherogenic index in rats.
\end{abstract}

Key words: kimchi fermented sausage, Lactobacillus plantarum, cholesterol, adipose tissue, atherogenic index

\section{Introduction}

Cardiovascular disease (CVD) is a leading cause of death in many countries around the world. By the year 2020, up to $40 \%$ of all death will be related to cardiovascular or heart disease (WHO, 2002). Higher serum total cholesterol level is generally considered to be a risk factor for coronary heart disease and atherosclerosis. Therefore, the reduction of plasma cholesterol level decreases the incidence and mortality of ischemic heart disease (IHD) and atherosclerosis (Greenwald, 1991).

Meanwhile, consumption of fermented dairy products containing probiotics has been proposed as a means to lower serum cholesterol (Kawase et al., 2000; St-Onge et al., 2000). This fact stimulates interests in the cholesterol

\footnotetext{
*Corresponding author: Chi-Ho Lee, Department of Food Science and Biotechnology of Animal Resourced, Konkuk University, Seoul 143-701, Korea. Tel: 82-2-450-3681, Fax: 82-2453-1948, E-mail: leech@konkuk.ac.kr
}

lowering effects of fermented milks and lactic acid bacteria (Mann and Spoerry, 1974). Many studies have been performed with experimental animals and humans to elucidate the effect of fermented dairy products on serum cholesterol, especially with selected strains of lactic acid bacteria (St-Onge et al., 2000). Hypocholesterolemic effect of fermented milk products in animals was reported (Rao et al., 1981; Rodas et al., 1996; Taranto et al., 1997). Standard yogurt and bifidus yogurt inoculated with Bifidobacteria and Lactobacilli commonly used as probiotics (Been and Prasad, 1997).

Kimchi is one of traditional functional food from Korea, and its probiotic effect has been reported in many research articles (Chang et al., 2010; Lee et al., 2005; Lee et al., 2011; Wang et al., 2010). Lee and Kunz (2005) had reported that when its raw form or freeze-dried powder form has been added in fermented sausages, the antioxidant effect has been investigated.

However, there was not enough information about the probiotics of Kimchi added fermented meat products. There- 
fore, the purpose of this study is investigating the plasma lipid and cholesterol levels in fermented sausage-diet rats in order to investigate the probiotic effect of Kimchi powder addition.

\section{Materials and Methods}

\section{Preparation of Kimchi and $L$. plantarum fermented sausage samples}

The preparation of Kimchi was carried out based on the Baechu-kimchi recipe (Lee et al., 2005) and the fermentation condition was $10^{\circ} \mathrm{C}$ for $15 \mathrm{~d}$ (Table 1). Kimchi was grounded and freeze-dried to prepare the Kimchi fermented sausage. Fermented sausage was prepared by modified method of Lee et al. (2005). The meat mixture was stuffed in natural casing with minced freeze-dried kimchi powder or L. plantarum at levels of $5 \%$, respectively and fermented at $15^{\circ} \mathrm{C}$ for $15 \mathrm{~d}$.

\section{Animal experiments}

Thirty male SD rats $(177 \pm 1.0 \mathrm{~g}$ body weight, four-wk old) were purchased from Central Laboratory Animal Inc. (Korea). They were housed in air-conditioned room at 22$24^{\circ} \mathrm{C}$ with $60-70 \%$ humidity and 12 -h light-dark cycles (07:00-19:00). The base composition of the experimental diet is shown in Table 2 . The rats were randomly divided into three groups and fed one of the following diets: nonfermented sausage added normal diet (CON), Kimchi fer-

Table 1. Composition of baechu-kimchi materials

\begin{tabular}{cc}
\hline \hline Materials and ingredients & Percentage \\
\hline Salted Chinese Cabbage & 90 \\
Leek & 4 \\
Red pepper powder (Korean) & 2 \\
Garlic & 2 \\
Ginger & 1 \\
Sugar & 1 \\
\hline
\end{tabular}

(Lee et al., 2005) mented sausage added normal diet (KIM), and 5\% Lactobacillus plantarum fermented sausage added nor- mal diet (PLA). The experimental diets were manufactured based on AIN-76 (Reeves et al., 1993). The feed and water were administered ad libitum. After $6 \mathrm{wk}$, the rats were anesthetized by Zoletil (Zoletil 50, Virbac, France) injection and the blood was collected from the abdominal aorta. Subsequently, the liver, heart, kidney and spleen were quickly removed, weighted and frozen in liquid nitrogen in separated portions. Perirenal adipose tissue (PAT) and epididymal adipose tissue (EAT) were also immediately removed and weighed.

\section{Body weight and food intake}

The total amount of food intake for each rat was recorded daily and their body weight was measured once a week during the raising period.

\section{Serum lipid determination}

Serum was acquired by centrifugation of blood samples in the condition of $3,000 \mathrm{~g}$ for $15 \mathrm{~min}$ at $4^{\circ} \mathrm{C}$. The level of total cholesterol (TC), high-density lipoprotein (HDL) cholesterol, low-density lipoprotein (LDL) cholesterol, triglyceride (TG), total lipid, free cholesterol, and phospholipids were analyzed by using Cholesterol E Test Wako (Wako Pure Chemical Industries Ltd., Japan), respectively (Friedewald et al., 1972).

\section{Atherogenic index calculation}

The AI (Atherogenic Index) was calculated as:

$\mathrm{AI}=($ total cholesterol $-\mathrm{HDL}$ cholesterol $) / \mathrm{HDL}$ cholesterol

\section{Statistical analysis}

The calculations were performed using the SAS (statistical analysis system, USA). All data are expressed as mean \pm SD (standard deviation). One way ANOVA was used to

Table 2. Composition of experimental diets (\%)

\begin{tabular}{cccc}
\hline \hline Ingredients & Non-fermented sausage & Kimchi fermented sausage & L. plantarum fermented sausage \\
\hline Casein & 20 & 20 & 20 \\
Corn starch & 60 & 60 & 60 \\
Non-fermented sausage & 5 & - & - \\
Kimchi fermented sausage & - & 5 & - \\
L. plantarum fermented sausage & - & - & 5 \\
Soybean oil & 10 & 10 & 10 \\
Mineral mixture & 4 & 4 & 4 \\
Vitamin mixture & 1 & 1 & 1 \\
Total volume & 100 & 100 & 100 \\
\hline
\end{tabular}

CON: Meat mixture without kimchi or starter culture. KIM: Meat mixture $+10 \%$ kimchi powder. PLA: Meat mixture $+5 \%$ starter mixture with commercial L. plantarum, $1.0 \times 10^{7} \mathrm{CFU} / \mathrm{mL}$. 
Table 3. The change of body weight and food intake for 6 wk

\begin{tabular}{ccccc}
\hline \hline \multirow{2}{*}{ Group } & \multicolumn{3}{c}{ Body weight $(\mathrm{g})$} & Food intake \\
\cline { 2 - 4 } & Initial & Final & Weight gains $^{\mathrm{g} / \mathrm{d})}$ \\
\hline CON & $176.3 \pm 4.4^{\mathrm{NS}}$ & $406.1 \pm 12.6^{\mathrm{a}}$ & $229.8 \pm 8.2^{\mathrm{a}}$ & $42.1 \pm 5.1^{\mathrm{a}}$ \\
KIM & $177.4 \pm 2.4$ & $382.8 \pm 6.0^{\mathrm{b}}$ & $205.4 \pm 3.6^{\mathrm{c}}$ & $27.8 \pm 5.1^{\mathrm{b}}$ \\
PLA & $179.5 \pm 5.1$ & $396.2 \pm 10.9^{\text {ab }}$ & $216.7 \pm 5.1^{\mathrm{b}}$ & $33.4 \pm 5.2^{\mathrm{ab}}$ \\
\hline
\end{tabular}

All values are mean \pm SD. $(n=10)$.

CON: non-fermented sausage added AIN-76 diet. KIM: kimchi fermented sausage added AIN-76 diet. PLA: L. plantarum $\left(1.0 \times 10^{7}\right.$ $\mathrm{CFU} / \mathrm{mL}$ ) fermented sausage added AIN-76 diet.

${ }^{\mathrm{abc}}$ Superscripts with different letters are statistically different $(p<$ $0.05)$.

${ }^{\mathrm{NS}}$ not significant.

determine the significance of the differences among the variables of the three experimental groups and followed by Duncan's multiples range test for difference between means. The level of significance was $p<0.05$.

\section{Results and Discussion}

\section{Body weight, food intake and organ weights}

The initial body weight and the amount of food intake were not significantly different among the groups. CON group has significantly higher food intake, body weight gains, and final body weight than the other groups $(p<$ 0.05 , Table 3 ). The body weight of KIM was significantly lower than that of the other groups $(p<0.05)$. We estimated that the phenomenon of reduced body weight of KIM and PLA was induced by the reduced food intake and by other factors including the probiotic effect of kimchi fermented bacteria in the kimchi powder. However, there were no significant differences in weights of heart, liver, kidney,
Table 5. Serum lipid level in rats

\begin{tabular}{cccc}
\hline \hline Group & Triglyceride & Total lipid & Phospholipid \\
\hline CON & $56.0 \pm 2.00^{\mathrm{NS}}$ & $224.4 \pm 18.54^{\mathrm{a}}$ & $96.3 \pm 9.32^{\mathrm{NS}}$ \\
KIM & $52.4 \pm 7.62$ & $190.2 \pm 14.92^{\mathrm{b}}$ & $95.6 \pm 3.42$ \\
PLA & $54.4 \pm 7.70$ & $218.5 \pm 9.53^{\mathrm{ab}}$ & $98.8 \pm 4.58$ \\
\hline
\end{tabular}

All values are mean \pm SD. $(n=10)$.

CON: non-fermented sausage added AIN-76 diet. KIM: kimchi fermented sausage added AIN-76 diet. PLA: L. plantarum $\left(1.0 \times 10^{7}\right.$ $\mathrm{CFU} / \mathrm{mL}$ ) fermented sausage added AIN-76 diet.

${ }^{\text {abc }}$ Superscripts with different letters are statistically different $(p<$ $0.05)$.

${ }^{\mathrm{NS}}$ not significant.

spleen, PAT, and EAT among the three groups (Table 4).

Plasma lipids, cholesterol level and atherogenic index

The serum lipid composition was presented in Table 5. The mean value of serum TG concentration in KIM and PLA groups was not significantly different. Serum total lipid in KIM group was significantly reduced than that of the CON group $(p<0.05)$.

The concentration of plasma TC, HDL, LDL, free cholesterol, and AI in CON were significantly higher than those of KIM group $(p<0.05)$. Especially, free cholesterol level of KIM and PLA was significantly $(p<0.05)$ lower than that of CON group. These results suggest that the kimchi powder or L. plantarum consumption may adjusts the serum lipid and cholesterol levels in rats, as well as the increased risk of senile arteriosclerosis which was induced by meat product consumption might by also reduced.

L. plantarum is one of the most well studied probiotics with hypocholesterolemic effects (Jeun et al., 2010). The mechanism of lipid regulation associated with L. plan-

Table 4. The weight of organs in rats

\begin{tabular}{ccccccc}
\hline \hline Group & Heart & Liver & Kidney & Spleen & Peri-renal adipose tissue & Epididymal adipose tissue \\
\hline CON & $1.15 \pm 0.08$ & $10.9 \pm 0.68$ & $2.67 \pm 0.21$ & $0.66 \pm 0.05$ & $7.2 \pm 1.85$ & $7.8 \pm 0.54^{\mathrm{NS}}$ \\
KIM & $1.14 \pm 0.07$ & $10.2 \pm 0.55$ & $2.67 \pm 0.23$ & $0.75 \pm 0.01$ & $7.5 \pm 0.77$ & $7.9 \pm 0.40$ \\
PLA & $1.13 \pm 0.09$ & $11.1 \pm 0.36$ & $2.56 \pm 0.08$ & $0.71 \pm 0.11$ & $6.2 \pm 1.28$ & $6.6 \pm 1.60$ \\
\hline
\end{tabular}

All values are mean \pm SD. $(n=10)$.

CON: non-fermented sausage added AIN-76 diet. KIM: kimchi fermented sausage added AIN-76 diet. PLA: L. plantarum (1.0×107 CFU/ $\mathrm{mL}$ ) fermented sausage added AIN-76 diet.

${ }^{\mathrm{NS}}$ not significant.

Table 6. The cholesterol level and atherogenic index of serum in rats

\begin{tabular}{cccccc}
\hline \hline Group & Total cholesterol & HDL cholesterol & LDL cholesterol & Free Cholesterol & AI \\
\hline CON & $70.1 \pm 7.67^{\mathrm{a}}$ & $52.7 \pm 8.54^{\mathrm{a}}$ & $13.0 \pm 2.62^{\mathrm{a}}$ & $3.42 \pm 0.97^{\mathrm{a}}$ & $0.33 \pm 0.10^{\mathrm{a}}$ \\
KIM & $54.6 \pm 4.62^{\mathrm{b}}$ & $42.8 \pm 3.92^{\mathrm{b}}$ & $9.4 \pm 1.52^{\mathrm{b}}$ & $2.42 \pm 0.97^{\mathrm{b}}$ & $0.17 \pm 0.19^{\mathrm{b}}$ \\
PLA & $61.3 \pm 8.81^{\mathrm{ab}}$ & $49.1 \pm 9.53^{\mathrm{ab}}$ & $10.8 \pm 1.58^{\mathrm{ab}}$ & $1.50 \pm 0.55^{\mathrm{c}}$ & $0.18 \pm 0.07^{\mathrm{b}}$ \\
\hline
\end{tabular}

All values are mean \pm SD. $(n=10)$.

CON: non-fermented sausage added AIN-76 diet. KIM: kimchi fermented sausage added AIN-76 diet. PLA: L. plantarum (1.0×107 CFU/ $\mathrm{mL}$ ) fermented sausage added AIN-76 diet. AI: Artherogenic Index.

${ }^{\mathrm{abc}}$ Superscripts with different letters are statistically different $(p<0.05)$.

${ }^{N S}$ not significant. 
tarum has been described as cholesterol assimilation by the bacteria and bile salt hydrolase deconjugate of bile salt (Jeun et al., 2010). Also Cha et al. (2012) reported that L. plantarum CIB 001 from kimchi decreased serum triglyceride, total cholesterol and LDL cholesterol levels in hypercholesterolemic rats. These similar results suggest that kimchi fermented sausage also has serum lipid and cholesterol lowering effects in animal models.

\section{Conclusions}

This study was designed for investigating the plasma lipid and cholesterol lowering effect of Kimchi powder or L. plantarum added fermented sausage in rats. The present results suggested that Kimchi powder intake may very effective to decrease serum lipid, cholesterol levels and AI in rats. Therefore, Kimchi powder fermented sausage plays very important roles to produce the low cholesterol functional meat products.

\section{Acknowledgements}

This research is supported by Konkuk University in 2012.

\section{References}

1. Been, A. and Prasad, V. (1997) Effect of yogurt and bifidus yogurt fortified with skim milk powder, condensed whey and lactase-hydrolyzed condensed whey on serum cholesterol and triacylglycerol levels in rats. J. Dairy Res. 64, 453-457.

2. Cha, S. D., Yu, J. W., Kim, T. W., Cho, H. S., and Lee, D. H. (2012) Effects of Lactobacillus plantarum CIB 001 on lipid metabolism of hypercholesterolemic rats. Korean J. Food Sci. Technol. 44, 324-330.

3. Chang, J. H., Shim, Y. Y., Cha, S. K., and Chee, K. M. (2010) Probiotic characteristics of lactic acid bacteria isolated from kimchi. J. Appl. Microbiol. 109, 220-230.

4. Friedewald, W. T., Levy, K. I., and Fredrickson, D. S. (1972) Estimation of the concentration of low-density lipoprotein cholesterol in plasma, without use of the preparative ultracentrifuge. Clin. Chem. 18, 499-502.

5. Greenwald, C. G. (1991) Overview of fat and cholesterol reduction technologies. In: Fat and Cholesterol Reduced Foods: Technologies and strategies. Haberstroh, C. and Morris, C. E. (eds.), Advances in Applied Biotechnology Series. 12, 21-34.
6. Jeun, J., Kim, S., Cho, S. Y., Park, H. J., Seo, J. G., Chung, M. J., and Lee, S. J. (2010) Hypocholesterolemic effects of Lactobacillus plantarum KCTC 3928 increased bile acid excretion in C57BL/6 mice. Nutrition 26, 321-330.

7. Kawase, M., Hashimoto, H., Hosoda, M., Morita, H., and Hosono., A. (2000) Effect of administration of fermented milk containing whey protein concentrate to rats and healthy men on serum lipids and blood pressure. J. Dairy Sci. 83, 255-263.

8. Lee, J., Hwang, K. T., Heo, M. S., Lee, J. H., and Park, K. Y. (2005) Resistance of Lactobacillus plantarum KCTC 3099 from Kimchi to oxidative stress. J. Med. Food 8, 299-304.

9. Lee, J., Yun, H. S., Cho, K. W., Oh, S., Kim, S. H., Chun, T., Kim, B., and Whang, K. Y. (2011) Evaluation of probiotic characteristics of newly isolated Lactobacillus spp.: immune modulation and longevity. Int. J. Food Microbiol. 148, 80-86.

10. Lee, J. Y. and Kunz, B. (2005) The antioxidant properties of baechu-kimchi and freeze dried kimchi-powder in fermented sausages. Meat Sci. 69, 741-747.

11. Mann, G. V. and Spoerry, A. (1974) Studies of a surfactant and cholesterol in the Massai. Am. J. Clin. Nutr. 27, 464-469.

12. Rao, D. R, Chawan, C. B., and Pulusani, S. R. (1981) Influence of milk and thermophilus milk on plasma cholesterol levels and hepatic cholesterogenesis in rats. J. Food Sci. 46, 1339-1341.

13. Reeves, P. G., Nielsen, F. H., and Fahey, G. C. Jr. (1993) AIN93 purified diets for laboratory rodents: Final report of the American Institute of Nutrition ad hoc writing committee on the reformulation of the AIN-76A rodent diet. J. Nutr. 123, 1939-1951.

14. Rodas, B. Z., Gilliland, S. E., and Maxwell, C. V. (1996) Hypocholesterlemic action of Lactobacillus acidophilus ATCC 43121 and calcium in swine with hypercholesterolemia induced by diet. J. Dairy Sci. 79, 2121-2128.

15. St-Onge, M. P., Farnworth, E. R., and Jones, P. J. (2000) Consumption of fermented and non-fermen.ted dairy products: Effects on cholesterol concentrations and metabolism. Am. J. Clin. Nutr. 71, 674-681.

16. Taranto, M. P., Sesma, F., Holbano, R., and Valdez, G. F. (1997) Bile salt hydrolase plays a key role on cholesterol removed by Lactobacillus reuteri. Biotechnol. Lett. 19, 245-247.

17. Wang, Y., Chen, C., Ai, L., Zhou, F., Zhou, Z., Wang, L., Zhang, H., Chen, W., and Guo, B. (2011) Complete genome sequence of the probiotic Lactobacillus plantarum ST-III. J. Bacteriol. 193, 313-314.

18. World Health Organization (WHO). (2002) Prevention of coronary heart disease: report of a WHO expert committee. World Health Organ. Tech. Rep. Ser. 678.

(Received 2013.5.21/Revised 2013.6.28/Accepted 2013.7.1) 